|| ISSN(online): 2589-8698 || ISSN(print): 2589-868X || International Journal of Medical and Biomedical Studies

Available Online at www.ijmbs.info

PubMed (National Library of Medicine ID: 101738825)

Index Copernicus Value 2018: 75.71

\title{
SOCIAL AND MEDICAL PROBLEMS AMONG THE PATHIPARA TRIBAL POPULATION OF WAYANAD, KERALA
}

\author{
Anirudh V. Mutalik*1 ${ }^{1}$, Sujesh $\mathrm{PK}^{2}$, Durgesh Kumar ${ }^{3}$ \\ ${ }^{1}$ Assistant Professor, Dept. of Community Medicine, KMCT Medical College, Mukkam, Kerala. \\ ${ }^{2}$ MSW, Dept. of Community Medicine, KMCT Medical College, Mukkam, Kerala. \\ ${ }^{3}$ Statistician, Dept. of Community Medicine, KMCT Medical College, Mukkam, Kerala.
}

Article Info: Received 18 March 2019; Accepted 03 April. 2019

Cite this article as: Mutalik, A., PK, S., \& Kumar, D. (2019). SOCIAL AND MEDICAL PROBLEMS AMONG THE PATHIPARA TRIBAL POPULATION OF WAYANAD, KERALA. International Journal of Medical and Biomedical Studies, 3(4).

DOI: https://doi.org/10.32553/ijmbs.v3i4.185

Address for Correspondence: Anirudh V. Mutalik, Assistant Professor, Dept. of Community Medicine, KMCT Medical College, Mukkam, Kerala.

Conflict of interest: No conflict of interest.

\section{Abstract}

Introduction:Tribes are one of the autochthonous people of the country.In India 427 groups are being recognized as Scheduled Tribe (ST). They form approximately $8 \%$ of total Indian population forming 104 million according to last census in 2011. The purpose of this study is to identify the socio demographic profile of Pathipara Tribal colony, to identify the customs, social problems and health problems existing in the tribal community and to provide health awareness and education regarding personal hygiene.

Objectives: The aim is to identify various social problems existing in the tribal population of Pathipara, Nellipoyil, Wayanad district.

Material \& Methods: A descriptive study was done to look for various problems. A standardised open ended pre-structured questionnaire was used for the study.

Observations: It was found that illiteracy stands out as an important issue. There is prevalence of communicable diseases like Tuberculosis among adults, Hepatitis B and Scabies among children. Conclusion:There is prevalence of malnutrion, anemia, infectious and non communicable diseases among the tribes of Pathipara and the major social problem faced by them is domestic violence under the influence of alcohol.

Keywords: Pathipara, Tribal population, Alcohol addiction, Tobacco addiction

\section{INTRODUCTION:}

Tribes are one of the autochthonous people of the country. Tribes in India are referred by names such as Aadivasi, Vanyajathi ,Vanavasi, Pahari etc. India is the second largest tribal population in the world, the first being Africa. Tribal communities are the integral part of Indian society. India has a wide variety of ecosystems with different communities and it represents with tribal population throughout its geographical locations depicting on a very complex cultural mosaic. ${ }^{1}$

The area inhabited by the tribes constitutes a significant part of the underdeveloped areas of 
the country but the tribes have rich traditions, culture and heritage with unique lifestyle and customs. The Scheduled area and Scheduled Tribes commission appointed by president of India on 08 April 1960 pursuant to article 339 of Constitution of India in its record of 14 October 1961 stated that "as these groups are presumed to form the oldest ethnological sector of the population, the term Aadivasi has become the current among certain people. 2

Vanajati - Caste of forest, Vanavasi- Inhabitants of forest, Pahari- Hill dwellers, Aadivasi- First settlers.

In India 427 groups are being recognized as Scheduled Tribe (ST). They form approximately $8 \%$ of total Indian population forming 104 million according to last census in $2011 .^{3}$ They inhabit varying ecological and geo climatic conditions (hills, forest, deserts) in different concentration across the country with different cultural and socio economic background.

There is bewildering varieties in population size of scheduled tribes ranging from 31 Jarvas of Andaman and Nicobar island to more than 7 billion Bhils of Rajasthan, Madhya Pradesh ,Maharashtra ,Gujarat(1981 census). Highest number of tribes resides in state of Orissa and lowest number of tribes in Sikkim. Largest tribal population around 15.4 millions resides in Madhya

Pradesh.

In Kerala most of the tribal people of live in the forests and mountains of Western Ghats, bordering Karnataka and Tamil Nadu. According to the 2011 census of India, the Scheduled Tribe population in Kerala is 3,64,189 (lunas - 180,169 and felunas - 184,020). Wayanad has the highest number of tribes $(1,36,062)$. These include Paniyas(69,116) , Kurichyan $(25,266)$, Kuruman(20,983), Kattunaykkan (17,051), Adiyan(11,196), Vettakuruman $(6,472)$ ,Thachanadan Mooppan(1,646), Wayanad Kadar (1473), Mala Arayan(176), Karimbalan(145), Ulladan (94)
Total population of Wayanad district as per Census 2011 is 816558.

- $\quad$ Scheduled Tribe population is 151443 (18.5 \%)

- Literacy Rate of Scheduled Tribe is: $65 \% .3,4$

Tribes usually remains isolated, majority of them have poor health status and have peculiar needs which is not similar to other people. Inadequate and difficult to access the health facilities for health needs of the tribes makes things more difficult. Tribal population of India face social problems like poverty, illiteracy, indebtedness, superstitions related to health, substance abuse and addiction (alcohol, tobacco, beetelnut),deficiency diseases(goiter),infectious diseases like Tuberculosis, Malaria,Leprosy and genetic abnormalities like Sickle cell anemia, G6PD deficiency, cultural problems, infertility and STD. Lack of personal hygiene \& health education, illiteracy and inaccessibility to affordable health services are the main factors for their ill health.

For this project we have selected Pathipara tribal colony and conducted personal interviews in presence of NGOs and Asha workers. The purpose of this study is to identify the socio demographic profile of Pathipara Tribal colony, to identify the customs, social problems and health problems existing in the tribal community and to provide health awareness and education regarding personal hygiene.

\section{Objective:}

AIM:

To identify various social problems existing in the tribal population of Pathipara, Nellipoyil, Wayanad district

\section{OBJECTIVES:}

1. To describe socio demographic profile of tribal population of Pathipara, Nellipoyil,

2. To identify and describe social problems of tribal population of Pathipara, Nellipoyil 
3. To identify and describe health problems of infectious origin, Non infectious diseases and problems of Women and child health.

\section{Material \& Methods:}

Type of study: Community based descriptive study

Target and sample population: tribal population residing at Pathipara

Study period: From 10th November 2017 to 19th April 2018

\section{DATA COLLECTION PROCEDURES}

An interviewer administered semi structured, predesigned and pretested questionnaire with primary open ended questions and optional follow up questions .Questions targeted were general community characteristics, perceived current substances of use or abuse, socioeconomic and demographic profile, literacy rate and health status. Anthropometric assessments to measure height, weight and BMI were carried out using standard protocols and equipments on the tribal population.

\section{INCLUSION CRITERIA}

People residing at Pathipara for more than 10 years and those who give informed consent.

\section{EXCLUSION CRITERIA}

People not giving informed consent

\section{STUDY INSTRUMENTS:}

Semi structured, predesigned and pretested questionnaire Measuring Tape, Weighing machine Stethoscope, Digital sphygmomanometer

\section{Observations:}

\section{AGE DISTRIBUTION}

Out of total population of Pathipara, $4.05 \%$ belongs to age group less than 1year, $7.79 \%$ belongs to age group between 1-5 years, $25.67 \%$ between the age of $6-15$ years, $43.24 \%$ between the age of $16-45 y e a r s, 13.5 \%$ belongs to age between $46-60$ years and $5.04 \%$ belongs to age greater than 60 years.

\section{GENDER DISTRIBUTION}

Out of total population of Pathipara $37.83 \%$ are males and $62.16 \%$ are females.

\section{EDUCATION}

Education is the key to tribal development. Almost all inhabitants of this tribal area are illiterates and only a few of them have received primary education. Thus illiteracy stands out as an important issue. The State Government is providing facilities for education. But the outcome is not as expected because of the non cooperative mentality of children and family and there are a large number of dropouts every year. Only $20 \%$ of children here take proper education and are hostlers. On Sundays, NGOs take classes for children which include not only academic aspects but also awareness regarding personal hygiene, communicable diseases etc. They also undertake recreational activities like playing games, colouring, craft works etc. These NGOs conduct summer camps for two months during which children are taken to visit different places .Government reports indicate that there is no scarcity of schools, other facilities or scholarships for the implementation of tribal education schemes but people are unaware of the importance of education.

\section{HOUSING}

All the houses in Pathipara tribal area are thatched houses built by government 5 years ago. Toilet facilities with water supply are made available for each house .All houses have 4 rooms including kitchen. Most of the houses have electric supply. There is inadequate ventilation and overcrowding in each house. There are active mosquito breeding places in and around the tribal colony.

There is a particular custom in the tribal community regarding housing. They leave the house following death of a family member and no one else use that house thereafter. Because of this 12 houses are vacant in the colony among the 36 built by government.

HEALTH STATUS 
None of the inhabitants of Pathipara has health insurance except the family that moved in 50 years back. The tribes have access to almost cost free health facilities provided by government under Tribal welfare schemes. Only a few go to the nearby hospitals by themselves. Rest of them are brought to hospitals by Asha workers and NGOs. They usually visit government hospitals in Kodanchery and Thamarassery and complicated cases are referred to Calicut Medical College. Most of the tribes prefer not to go to hospitals when they are sick.

\section{INFECTIOUS DISEASES}

In the tribal population of Pathipara there is prevalence of tuberculosis. They are generally uncooperative to the treatment. Some are taking regular medication under the influence of Asha workers Unawareness and carelessness among them is a major cause leading to the higher risk of transmission of disease among them. The patients suffering from TB is found to take no measures to prevent further transmission of the disease and due to unhygienic health practices infectious diseases are more common Hepatitis B is prevalent among children. Adults have yet not been properly screened and therefore the prevalence of the disease among them is not yet clear

It was found that prevalence of scabies is more in children among the general tribal population. Because of crowded living conditions which in turn results in close contact with the infected, the spread of scabies is very high. The unavailability of adequate treatment facilities also seems to be a major contributing factor.

\section{NON INFECTIOUS DISEASES}

Among the study conducted, the sickle cell disease was noticeably prevalent in the tribal population. The state of malnutrition might have predisposed to the genetic mutation owing to the development of sickle cell disease among them. Even though they have been diagnosed with the disease, due to inadequate treatment and health facilities it still persists as a major concern that have to be rectified .By comprehensive medical management ,longevity and quality of their life can be improved .

Even though hypertension has been detected among the tribes of Pathipara, it has not yet raised to a level of serious health concern that requires immediate intervention. But there is a probability that in future, it may become an important issue of concern and should not be neglected as the consumption of alcohol is very high in this tribe.

\section{WOMEN'S HEALTH}

The health status of woman in this population of Pathipara according to the study shows that malnutrition is common and greatly affected ability to resist infection leading to chronic illnesses and that of post weaning period leading to many childhood diseases. Nutritional anemia is a major problem of woman in the community. $2 / 3$ rd of the population has anemia which affects physiological and physical health. Maternal malnutrition is evident. Especially for those who are having closely spaced pregnancies and retreat complex socioeconomic factors that affect their overall situation. Among adult women, gynecological complaints and deficiency diseases are common. The complication of pregnancy, child birth and abortion and lack of proper medical care and facilities are leading to an increased risk of maternal death. Genetic disorders namely sickle cell anemia is found to occur in the population. The cultural norms that particularly effect women are attitude towards marriage, age of marriage and marriage practices, values attached to fertility and sex of child and pattern of family organization and her status in the society.

\section{CHILD HEALTH}

Most of the children appear to be healthy and moderately nourished. Food is supplied by government and various NGO s but however there are few children showing signs of malnutrition. Complete vaccination for age has been given to all with the help of Asha workers. Children are prone to infectious disease due to unhygienic etiquette and poor sanitary habits. 
There has been a recent outbreak of scabies among children .Sickle cell anemia, G6PD deficiency and Hepatitis B are other diseases seen among the children. Children are taken to hospital for proper treatment and care with the help of government services. Health education classes are given by the NGO s once in every month. Medical camps are conducted to assess their health status once in a while.

\section{SOCIAL PROBLEMS}

Social problems are always a major concern of a society. Alcoholism and Tobacco addiction seems to be the root cause of major issues faced by the families of Pathipara tribes. The women suffer from domestic violence by their husbands under the influence of Alcohol. Even children are found to have history of substance abuse. There is a high rate of consanguineous marriage among them which may lead to many congenital abnormalities. There is marked lack of hygienic practices which could predispose to many infectious diseases. Lack of proper education and awareness seems to be a major cause for the social problems faced by them. Providing basic education and bringing awareness about proper social behavior could solve the problems to an extent.

Discussion:In Pathipara tribal colony nearly $4.05 \%$ belongs to age group less than 1 year,7.79\% belonged to under five age group, $25.67 \%$ between the age of $6-15 y e a r s, 43.24 \%$ between the age of $16-45 y$ years, $13.5 \%$ belonged to age between $46-60 y e a r s$ and $5.04 \%$ belongs to age greater than 60 years.

In the tribal community of Pathipara, survey showed that the most of the women were underweight and anaemic and were consistent with studies done in Santhal tribe of Jharkhand.A variety of indigenous foods were reported to be consumed but most women are underweight and anaemic. The underlying condition may increase morbidity and mortality of women as they are more susceptible to diseases.

Just like the statistics had indicated, the prevalence of sickle cell anaemia seems to be high among the tribal population of pathipara tribal community.

In the tribal community of Pathipara, sickle cell trait is prevalent. The survival rate of patients with sickle cell anaemia seems to be higher and this study was in consistent with frequency of sickle cell anaemia among the tribal communities of Wayanad district, kerala.

In the community of Pathipara, survey showed that most of the people in the area used firewood as source of fuel. Primary use of firewood has resulted in deforestation, fuel wood was used in various activities like cooking, water heating, brewing etc. and were in consistence with study conducted on fuel wood consumption pattern in tribal areas of Arunachal Pradesh, north east India.

The study conducted by Rajpal S Kashyap et al $\mathbf{1 1}$ on Impact of socioeconomic status and living condition on latent tuberculosis diagnosis among the tribal population of Melghat is not completely consistent with the studies conducted in Pathipara .

When compared to study conducted by Mohindra K S et $\mathrm{al}^{\mathbf{8}}$ it is consistent with our study that alcohol consumption is the root cause of social problem in the Paniyas colony. Alcohol consumption is increasing among young population. Easy availability of alcohol from licentiate shops and employers offering alcohol to attract Paniyas for work are contributing to this extensive use of alcohol. Women, both old and young ladies are found to use alcohol every day. There is evidence of substance abuse among youngsters.

The study conducted by Meshram et al ${ }^{14}$ on increasing prevalence of hypertension among Paniyas is not consistent with our results. Hypertension is not prevalent among people in pathippara tribal colony.

The study conducted by Mohindra KS et $\mathbf{a l}^{\mathbf{8}}$ on availability and utilisation of health care is not consistent with our results. In pathipara tribal 
colonies they get cost free health services based on tribal welfare schemes. Most of them don't go to hospital on their own will. They are taken by ASHA worker and NGOs.

Study conducted by Rao KM et al $^{\mathbf{7}}$ on diet and nuitrional status of adult population is not completely consistent because most of the children are found to be healthy and moderately nourished. Only few showed signs of malnutrition which is not severe or significant. Good quality food is being provided by both Government services and NGOs. Complete vaccination is attained for the age with the help of ASHA worker.

Alcohol and tobacco addiction seems to be the root cause of major issues faced by families in the study area. People in all age groups of both sexes are found to be addicted to alcohol .This leads to malnutrition and associated diseases in people living in Pathipara.the results are consistent with the study done by Radin et al ${ }^{\mathbf{9}}$ in washiington state tribal communities.Although the substance vary with the culture the effect of SUAD seems to be the same in both studies.

Through the continuous effort from government and Non-Governmental Organizations there is a massive change in Nutritional habits, primary education immunization, quality medical care, hygiene practices etc. in Pathipara tribal community. After this survey we could say that through more sophisticated developmental plans supported with proper funding we could bring light in their lives.

\section{Conclusion:}

To conclude there is prevalence of malnutrition, anaemia, infectious and non communicable diseases among the tribes of Pathipara and the major social problem faced by them is domestic violence under the influence of alcohol.

\section{References:}

1. Bhuria Report of the Scheduled Areas and scheduled tribes commission government of India. Volume 1, 2002-2004
2. http://kirtads.kerala.gov.in/tribals-in-kerala/ Last accessed on 3/2/2018.

3. https://kerala.gov.in/ census2011; last accessed on 12/2/2018.

4. http://pib.nic.in/newsite/PrintRelease.aspx? relid=85918; last accessed on 12/2/2018 5 .

5. Haddad et al.: "Health divide" between indigenous and non-indigenous populations in Kerala, India: Population based study. BMC Public Health 2012 12:390.

6. R.K. Maikhuri,:Fuelwood consumption pattern of different tribal communities living in Arunachal Pradesh in North-East India, :Bioresource Technology, Vol -35, Issue- 3 ,1991 Page- 291-292

7. Kodavanti Mallikharjuna Rao,Nagalla Balakrishna, Avula Laxmaiah, Kodali Venkaiah and GNV Brahmam. Asia Pac J Clin Nutr 2006;15 (1):64-71

8. K S Mohindra, D Narayana, S S Anushreedha, Slim Haddad. Alcohol use and its consequences in South India: Views from a marginalised tribal population. Drug and Alcohol dependence, vol 117 issue 1 page 70-73

9. Sandra M Radin, Stephen H Kutz, June La Marr, Diane Vendiola, Michael Vendiola, Brian Wilbur, Lisa Rey Thomas, And Dennis Donovan,Community Perspectives on Drug/Alcohol Use, Concerns, Needs and Resources In Four Washington State Tribal CommunitiesJournal of ethnicity in substance abuse,Published on 2015/01/03 Vol-14,Page no:1-30,DO-10.1080/15332640. 2014.947459

10. Ravendra $k$ sharma,Mrigendra $P$ singh,Kalyan B saha,Praveen K bharathi, Vidhan jain, $P \quad P$ singh,Nipun silawat, $R$ patel,M hussain, S K chand,Aravind pandey, Study on socioeconomic and household risk factors of malaria in tribal area of madhya Pradesh, Indian journal of medical research,Published on may 2015 ;141(5):567-575, Doi-10.4103/0971-5916. 15 9515 ,PMCID : PMC4510754

11. Rajpal S Kashyap, Amit R Nayak, Aliabbas A Husain, Seema D Shekhawat, Ashish R 
Satav,1 Ruchika K Jain, Dhananjay V Raje,2 Hatim $F$ Daginawala, and Girdhar $M$ Taori,Journal : Lung India. 2016 Jul-Aug; 33(4): $\quad 372-380 .$, doi: $\quad$ 10.4103/09702113.184868,PMCID: PMC4948223.availabl at https://doi.org/10.1371/ journal. phone. 0089524

12. Kaur M, Das GP , Verma IC. Sickle cell trait \& disease among tribal communities in Orissa, Madhya Pradesh \& Kerala.The Indian Journal of Medical Research 01 Mar 1997, 105:111116 PMID:9119416)

13. Feroze $M$, Aravindan K P. Sickle cell disease in Wayanad, Kerala: gene frequencies and disease characteristics.National Medical Journal Of India 14(5): 267-70. September 2011

14. Meshram I I, Arlappa N, Balkrishna N, Rao K M, Laxmaiah A, Brahmam G. Prevalence of hypertension, its correlates and awareness among adult tribal population of Kerala state, India. J Postgrad Med [serial online] 2012 [cited 2018 Feb 3]; 58:255-61. Available from: http://www.jpgmonline.com /text.asp? 2012/58/4/255/105444
15. Suparna Ghosh Jerath,Archna Singh,Melina S Magsumbol,Tanica lyngdah, Preeti Kamboj, Gail Goldberg. study: contribution of indegenous food in nutritional health of woman, Journal of Hunger \& Environmental nutrition 11(4):1-21. Vol 11 .May 2016

16. Ramachandra Kamath , Majeed JA, Chandrasekaran V, Pattanshetty SM. TitlePrevalence of Anemia among Tribal Women of Reproductive Age in Udupi Taluk, Karnataka.,Journal of Family Medicine and Primary Care.Published on 2013;volume 2 issue 4,Page no:345-348. doi:10.4103/22494863.123881.

17. Jose JA,Sarkar S,Kumar SG,Kar SS,Utilization of maternal health care services by tribal women in kerala,Journal of natural science ,biology and medicine vol -5 issue 1january 2014 DOI 10.4103/0976-9668.127314

18. Mohindra K S , Low healthcare utilisation rates and opportunities to cope with illness among deprived indigenous group, Journal of epidemiology \& community health 60(12):1020-6 january 2017 DOI:10.1136 /jech2006.047647 